\section{El efecto del rumor en el cambio del voto: la ira, el miedo y la incertidumbre generados por el rumor en procesos electorales y sus contribuciones en las decisiones del votante}

\author{
doi:10.11144/Javeriana.syp35-69.ercv \\ Recibido: 24 de agosto de 2015 \\ Aceptado: I6 de agosto de 2016 \\ Disponible en línea: I I de noviembre de 2016 \\ Submission Date: August $24^{\text {th }}, 2015$ \\ Acceptance Date: August $16^{\text {th }}$, 2016 \\ Available Online: November $11^{\text {th }}$, 2016

\section{Origen del artículo} \\ Esta investigación fue financiada con fondos de la \\ Universidad del Azuay como parte de la Línea en \\ Investigación en Comunicación y Política de la Maes- \\ tría en Comunicación y Marketing del Decanato de \\ Investigaciones de la misma Universidad. El proyecto \\ se realizó entre el tercer trimestre de 2014 y el segundo \\ trimestre de 2015.
}

The Effect of Rumors on the Change of Voting Choice: Anger, Fear, and Uncertainty Generated by Rumors during Election Processes and their Effect on the Voters'

O efeito do boato na mudança da votação: raiva, medo e incerteza gerados pelo boato em processos eleitorais e suas contribuições nas decisões do eleitor Decision

Caroline Ávila

Ecuatoriana. Universidad del Azuay. Candidata a doctora y magíster en Comunicación por la Pontificia Universidad Católica de Chile. Decanato de Investigaciones. Av. 24 de Mayo 7-77 y Hernán Malo, Cuenca, Ecuador. Teléfono+59-3-7-4091000. cavila@uazuay.edu.ec

Gabriela Cabrera

Ecuatoriana. Magíster en Comunicación. Dircom en Elecaustro, Ecuador. Teléfono +59-3-7-4103073. gabrielacabreralopez@hotmail.com 


\section{Resumen}

El rumor es un componente reiterado en las campañas electorales, sin embargo, poco se ha estudiado sobre los efectos directos en las emociones y cómo estas inciden en el votante. Esta investigación presenta, con datos empíricos, evidencias de los efectos reales del rumor en emociones, como la ira, el miedo y la incertidumbre, a través de un estudio de las elecciones intermedias en Ecuador de febrero de 2014. La metodología es de tipo cuantitativo a través de encuestas aplicadas a los hogares objeto de este estudio. Los resultados fueron sometidos a análisis estadísticos de correlación de rho de Spearman y regresión logística que permiten explicar el cambio en el voto de acuerdo con las variables que evalúan la incidencia del rumor en emociones negativas, como la ira, la incertidumbre y el miedo. A efectos de este estudio, fue analizado el caso Tranvía Cuatro Ríos en la ciudad de Cuenca (500 000 habitantes).

Palabras clave: campañas electorales; marketing político; rumor; comunicación política; opinión pública

\section{Abstract}

Rumors are a constant component of election campaigns; however, there have not been many studies on the direct effect of emotions and how they affect the voter. This research presents, based on empirical data, evidence of the real effect of rumors on emotions such as anger, fear, and uncertainty, by means of a study of the intermediate February 2014 elections in Ecuador. We use a quantitative-type methodology, using surveys administered to the households' object of this study. The results were subject to statistic correlation analysis - Spearman's rho and logistic regression - which allow us to explain the change in the vote according to the variables explaining the incidence of rumors on negative emotions such as anger, uncertainty, and fear. The case Tranvía Cuatro Ríos in the city of Cuenca (500,000 inhabitants) was analyzed for the purposes of this study.

Keywords: election campaigns; political marketing; rumors; political communication; public opinion

\section{Resumo}

O boato é componente reiterado nas campanhas eleitorais, no entanto, pouco foi estudado dos efeitos diretos sobre as emoções e como elas afetam o eleitor. Esta pesquisa apresenta, com dados empíricos, provas dos efeitos reais do boato em emoções, como raiva, medo e incerteza, por meio de estudo das eleições intermédias no Equador em fevereiro de 2014. A metodologia foi quantitativa, através de inquérito aplicado nás famílias sujeitos deste estudo. Os resultados foram submetidos a análise estatística de correlação Rho de Spearman e regressão logística que permitem explicar a mudança na votação de acordo com as variáveis avaliando a incidência do boato em emoções negativas, como raiva, incerteza e medo. Para os fins deste estudo, o caso Tranvía Cuatro Rios, na cidade de Cuenca (de 500000 habitantes), foi analisado.

Palavras-chave: campanhas eleitorais; marketing político; boato; comunicação política; opinião pública 
Caroline Ávila y Gabriela Cabrera

\section{El efecto del rumor en el cambio del voto: la ira, el miedo y la incertidumbre generados por el rumor en procesos electorales y sus contribuciones en las decisiones del votante}

\section{Introducción}

Una campaña electoral es esencialmente un proceso de comunicación política utilizado para movilizar y convencer a los votantes, además de reforzar las identidades y simpatías existentes (Escalante, 2007; García y Ortiz, 2013). Las campañas electorales, a pesar de la proliferación de información, suelen ser procesos de gran incertidumbre. Si bien se utiliza mucho la difusión de información por medios masivos, el mensaje político todavía se mueve entre el lenguaje de masas y el lenguaje individual donde el contacto personal adquiere importancia (Escalante, 2007).

En la campaña política, es patente el proceso de formación de la opinión pública formulado por Zaller (1992), quien afirma que la formación y el cambio en las opiniones de los inviduos se genera tanto por la atención a temas políticos como por el grado de conocimiento o interés en política que los ciudadanos le prestan a la información entregada por la élite política.

Sciarini y Kriesi (2003) argumentan que el modelo de Zaller debe incorporar como variable lo que llaman "cristalización de la opinión”, debido a su incidencia en la resistencia al cambio. Cuanto más cristalizada sea la opinión del votante, es decir, que esté fuertemente insertada en una estructura ideológica consistente, menor oportunidad de cambio. Por otro lado, afirman que la dirección del flujo de información que recibe el votante incide en el cambio de opinión hacia la intención en la que va la información. Sin embargo, esta conclusión debe considerar el peso de la sensibilidad política, es decir, no será el mismo efecto entre quienes se oponen a la dirección que el mensaje toma que entre los que están a favor (Sciarini y Kriesi, 2003).

Con esto en mente, los estrategas políticos han tomado en consideración diversas herramientas para la diseminación de un mensaje político altamente persuasivo. Esa difusión incluye canales tradicionales, como televisión, radio y prensa, así como los recientemente desarrollados, como internet, redes sociales, canales de video, etc. (Fernández y Dell'Oro, 2011); sin embargo, no deja de ser utilizado (aunque estudiado en menor intensidad) uno de los más antiguos: el rumor.

Este trabajo realiza una aproximación al estudio de los efectos del rumor dentro de un proceso electoral. Para ello, se determinaron tres variables adjudicadas a rumores generados en un tema electoral, como es el caso Tranvía de la ciudad de Cuenca (Ecuador). Estas variables son ira, incertidumbre y miedo. Tanto la incertidumbre o ansiedad como el miedo son efectos cognitivos y emocionales analizados a partir de la publicidad 
negativa y las campañas negativas (Daignault y Soroka, 2013; Shemer, 2012; Peytibi, 2012). Sin embargo, las circunstancias del caso motivan a analizar también el efecto de la ira provocada por los rumores difundidos durante la campaña para la Alcaldía de Cuenca durante 2014. Los datos fueron levantados a través de encuestas aplicadas a la población, cuyos locales o domicilios se encuentran al frente de la construcción de la infraestructura para el tranvía, quienes en adelante serán identificados como los "frentistas".

El levantamiento de la información permitió confirmar los rumores escuchados durante la campaña y establecer su grado de credibilidad. Posteriormente, a través de análisis estadísticos (rho de Spearman y regresión logística), se determinó el efecto del rumor en el cambio del voto de acuerdo con cada una de las tres variables identificadas.

Este trabajo pretende contribuir al estudio del rumor en procesos políticos según la evidencia empírica de sus efectos en las emociones de los votantes y las reacciones que puede provocar en la fomación de la opinión pública.

\section{Marco teórico}

Los rumores son mensajes circulantes en las conversaciones de la gente sobre temas concer- nientes al interés general y público que no han sido confirmados por fuentes oficiales. Es un mensaje breve y espontáneo que se extiende con rapidez, "en ocasiones se entiende como una técnica de comunicación estratégica con el fin de influir en el público, pero buscando la confusión o la distracción” (Gallego, 2010, p. 3). Esta característica hace que el rumor sea concebido como un fenómeno social con connotación negativa, pues levanta en quien lo escucha una sospecha que produce incertidumbre, que, aunque no sea necesariamente falso, es considerado escasamente fiable (Sojo, 1998; Vélaz, 1993).

Desde una perspectiva más optimista, los rumores son considerados una acción colectiva de expresión y comunicación con alto contenido cognitivo y emocional, que genera un cierto grado de pertenenecia a un grupo entre quienes lo comparten, sobre todo en momentos de crisis o cuando existe alguna problemática, porque permite una descarga de tensión, de emociones y estados de ánimo (Fernández, 2012).

Allport y Postman (1947), en uno de sus primeros trabajos sobre el rumor, lo definen como una salida que precisan los individuos para proveer una explicación a sus ansiedades. El rumor no siempre se asocia a la falta de noticias, aunque 
sin lugar a duda el hecho de no tener información oficial es un gatillador de rumores; sin embargo, dependiendo de la importancia y del contexto, el rumor puede manifestarse inclusive por sobre las noticias oficiales ya anunciadas. Los rumores circulan cuando los eventos son importantes y cuando la información recibida es subjetivamente ambigua o limitada. La fórmula del rumor, según estos autores, radica en la importancia que los individuos le otorgan al tema, multiplicada por la ambigüedad de la información o evidencia. Si uno de los dos elementos no existe simplemente no hay rumor.

A su vez, la importancia por un determinado tema depende de la motivación, en este caso, manifestada en la urgencia emocional primaria que conduce a la búsqueda de información - aunque no sea confirmada- que le permita al interesado justificar esa urgencia y explicar por qué experimenta esas emociones. De hecho, los rumores se explican por la necesidad del ser humano de extraer significados de su entorno. En resumen, para Allport y Postman (1947), el rumor actúa como agente racionalizador: explicando, justificando y proveyendo significado.

Al modelo orginal de Allport y Postman (1947) se le han ido incorporando más elementos con miras a explicar la dinámica de propagación del rumor o la clasificación de sus receptores (desconocedores, diseminadores y bloqueadores). Por ejemplo, Zhao, Liu y Wang (2016) manifiestan que el poder persuasivo del rumor facilita su propagación debido a que motiva a quienes lo escuchan a que aprueben y apoyen las actitudes u opiniones manifestadas en el rumor, esto induce a que el comportamiento del receptor esté alineado con el contenido del rumor, lo cual promueve su difusión.

\section{Rumores y campaña política}

Según Muñiz (2010), el rumor como herramienta de marketing y comunicación es utilizado tanto en el ámbito empresarial como en la política. Asimismo Joe Napolitan al referirse al rumor en campañas políticas habla de la llamada "guerra sucia” provocada por la publicidad negativa, insi- diosa o dañina considerando en este enunciado las críticas ilegítimas que se les haga a los candidatos (Sojo, 1998).

Una de las formas más antiguas de comunicar algo es el rumor. Para Contreras (2001), no existe política sin rumores, pues dice que el rumor es un contrapoder y en terrenos de conquista y gestión de poder es natural que los rumores se proliferen. Los rumores pueden ser positivos o negativos o podrían ser probados como verdaderos o falsos, pero su rasgo principal de definición es que circulan sin confirmación (Weeks y Garrett, 2014).

Por su influencia y poder, al rumor político se le ha acreditado el fracaso de campañas electorales, la caída de Gobiernos y el desprestigio de presidentes y políticos. ${ }^{1}$ Asimismo también es de notar, según una investigación realizada por los politólogos McClosky y Chong (1985), que las personas más inclinadas a creer y esparcir rumores políticos son quienes encuentran en ellos compatibilidad con sus simpatías partidistas o ideológicas (Ochoa, 2012).

La época de campaña provee a los votantes un entorno informativo complejo en su búsqueda por información que guíe su voto. En ese entorno, cuanto más negativa sea la información sobre un candidato menos favorable será su inclinación hacia él. Por otro lado, los votantes prestan mayor atención a información negativa procedente de la campaña que a la información positiva. Esto fue analizado por un estudio de Weeks y Garret (2014), donde se pudo comprobar que un número de falsos rumores que fueron negativos respecto del binomio presidencial incidieron en un decrecimiento del voto favorable.

El rumor en campañas políticas es considerado una amenaza para los resultados del ejercicio democrático. Los votantes necesitan información precisa para tomar decisiones y los rumores que circulan, al no tener información confirmada, inciden de manera perjudicial en el proceso de decisión del votante (Weeks y Garrett, 2014).

Hay estudios que validan el efecto positivo de la campaña reflejada en la necesidad del votante por acceder a información y, a través de ella, 
confirmar su capacidad de entender y participar en política; este efecto es conocido como eficacia interna. Por otro lado, la campaña política también incide en la eficacia externa, es decir, en la percepción del votante de ser corresponsable de los efectos en el sistema político. Sin embargo, emergen discusiones críticas sobre si la campaña en verdad ayuda a que los votantes tengan información calificada para tomar sus decisiones, ya que los mensajes conflictivos, profusamente diseminados en las campañas, tienden a provocar confusión e incertidumbre en el votante (Hansen y Pedersen, 2014).

\section{El rumor y las reacciones afectivas negativas}

La atención a publicidad política genera negativas reacciones afectivas, como el miedo o la ansiedad, pero, al mismo tiempo, estas reacciones incrementan la atención de las personas a mayor información. De hecho, la publicidad negativa produce altos niveles de atención y altos niveles de activación psicológica; sin embargo, existe mayor resistencia a la persuasión generada por la publicidad, ya que respecto de contenidos la información negativa da lugar a mayor contraargumentación (Daignault, Soroka y Giasson, 2013; Schemer, 2012).

La apelación al miedo es uno de los motivadores más utilizados, puesto que las personas recuerdan más temas con contenido emocional. El miedo como táctica es utilizado en el discurso político como forma de influir en la opinión pública. Crea una asociación negativa con el oponente de tal manera que el público quede convencido de que elegir al candidato opositor tendrá consecuencias peligrosas para ellos (Peytibi, 2012). ${ }^{2}$ Un colectivo que toma sus decisiones según rumores lo está haciendo sobre la base de especulaciones, supuestos e historias incompletas y no autorizadas (Bacalao, 2012; García, 2006).

Dado que las reacciones afectivas, como el miedo y la ansiedad, han sido estudiadas como parte de los efectos de la publicidad negativa, corresponde revisar el efecto del rumor en este tipo de emociones, e incorporar en el modelo la ira como una reacción producto del rumor. Para ello, esta investigación plantea, como caso de estudio, el análisis de la influencia del rumor en las elecciones a la Alcaldía de Cuenca (Ecuador), de febrero de 2014.

\section{El caso Tranvía Cuatro Ríos}

El escenario de la campaña política de febrero de 2014 se prestó para la gestión de rumores que estuvieron centrados en varias temáticas, entre ellas la más repetitiva fue la concerniente al Proyecto Tranvía Cuatro Ríos y el paso de este por el centro histórico de Cuenca. ${ }^{3}$

En el periodo 2005-2009, la Alcaldía de Cuenca estaba ocupada por Marcelo Cabrera Palacios, del Movimiento Igualdad. En el periodo siguiente, es decir, 2009-2014, Cabrera, que se postuló a la reelección, fue derrotado por su principal opositor, Paúl Granda López, de Alianza PAÍS, partido del Gobierno.

Tanto en aquella campaña como en la Administración 2009-2014, Granda tenía como su principal promesa la implementación de un plan de movilidad integral para la ciudad, en la que se incluía la construcción de un medio de transporte masivo. Esta promesa se cumpliría con la puesta en marcha del proyecto denominado Tranvía Cuatro Ríos.

Según información obtenida del Departamento del Proyecto Tranvía del Municipio de Cuenca, en dichos estudios se contempla el trazado de una troncal de ida y vuelta que cruza la ciudad a través de catorce unidades de tranvía, que incluye el paso por el centro histórico. Además, indica el estudio que un tranvía tiene la capacidad de reemplazar a 4 autobuses y a 200 vehículos, el recorrido se estima en $10.7 \mathrm{~km}$ y 35 min por sentido. La promesa tras el proyecto fue la de brindar a la ciudad un transporte público masivo, innovador, sostenible, ecológico, confiable, ligero, dotado de equipos de última tecnología y que fuera armonioso con una ciudad de características patrimoniales, además de poseer varias ventajas ambientales y de movilidad por su sistema eléctrico. El costo de inversión es de US\$231 millones, de los cuales $70 \%$ fue com- 
prometido por el Gobierno Nacional (Gobierno Autónomo Descentralizado de Cuenca, 2014).

\section{Campaña electoral 2014 y vocería política}

Iniciado 2014 arranca la campaña para elecciones intermedias en el país, entre ellas la del alcalde de Cuenca. La votación se realizó el domingo 23 de febrero. Cuatro fueron los candidatos que se postularon: Paúl Granda López, de Alianza PAÍS; Marcelo Cabrera Palacios, de la Alianza IgualdadParticipa; Alejandro Cordero, del Partido Sociedad Patriótica; y Lucía Cardoso, de CREO. Las encuestas reflejaban una contienda muy reñida entre los dos primeros con una preferencia por el candidato incumbente, Paúl Granda.

Varios fueron los mensajes de campaña por parte del alcalde en funciones y candidato a la reelección, pero el peso mediático fue para el Proyecto Tranvía, cuyos trabajos de construcción de obras y adecuación de instalaciones estaban ya iniciados. Al ser Granda el proponente del Tranvía, su imagen estaba muy ligada al proyecto.

Por su parte, Marcelo Cabrera, exalcalde de la ciudad, de la Alianza Igualdad-Participa, durante sus discursos se refería mucho a las falencias de la Administración de Granda, y con respecto del Tranvía indicaba que tenía que analizar y observar los contratos firmados, para proceder en consecuencia de ellos. Estos contratos, a su criterio, fueron una decisión apresurada, sin embargo, afirmaba que debía continuar con el proyecto.

Este era el discurso que manejaban los dos candidatos favoritos en la campaña; sin embargo, hay que destacar que, si bien los dos hablaban del Proyecto Tranvía, se dejaba claro que el proponente era Granda y que Cabrera era el que hacía objeciones al proyecto a pesar de estar en construcción.

La campaña estuvo teñida por un sin número de rumores, muchos de ellos relacionados con el Proyecto Tranvía que apelaron al temor por los posibles daños en la infraestructura de las casas que estarán cerca de los rieles, costos de funcionamiento, inseguridad y accidentes en las vías, entre otros. El mensaje se dispersó de tal manera que dejó la impresión de que las aclaraciones oficiales para contrarrestar temores no fueron suficientes.

El resultado de aquella elección fue la derrota del principal promotor del Tranvía, Paúl Granda, quien obtuvo ocho puntos menos (\%) que el candidato ganador, Marcelo Cabrera (El Tiempo, 2014).

Con estos antecedentes, y de acuerdo con las variables identificadas desde la teoría, este estudio se plantea las siguientes hipótesis:

$\mathbf{H}_{1}=$ Los rumores en torno al Proyecto Tranvía generaron miedo/ira/incertidumbre en los frentistas del centro histórico.

$\mathbf{H}_{2}=\mathrm{El} \mathrm{miedo/ira/incertidumbre} \mathrm{generados}$ en los frentistas a causa de los rumores influyeron en el cambio del voto.

Ambas hipótesis se enuncian como hipótesis explicativas, y la relación está determinada como causa-efecto.

\section{Metodología}

Con el objetivo de determinar la influencia del miedo a través del rumor en las elecciones a la Alcaldía de Cuenca 2014, en el caso Tranvía Cuatro Ríos, se diseñó un estudio de alcance correlacionalexplicativo y no experimental con un enfoque de tipo cuantitativo, a través de la aplicación de una encuesta a los dueños de casas y negocios que se encuentran en las calles del centro histórico de la ciudad, por donde pasará el tranvía.

Luego de un breve sondeo realizado a algunos ciudadanos y a brigadistas de la campaña, se identificaron siete rumores asociados al tranvía, a los cuales la gente reaccionaba con sentimientos de temor, incertidumbre y molestia. Con la finalidad de validar estos rumores y medir su efecto en las emociones negativas y posteriormente en el voto, se realizó una encuesta a los habitantes y dueños de comercios ubicados en las calles del centro histórico de la ciudad con mayor afectación por las obras del tranvía. Se identificaron 954 predios $^{4}$ con estas características. 
Al plantear la fórmula de obtención de la muestra, con un nivel de confianza de $95 \%$ y un margen de error de $\pm 5 \%$, se requirió la aplicación de 274 encuestas. Con la información adquirida, se efectuó la tabulación de los datos. Los resultados obtenidos se presentan a través de varios cuadros, cruces y análisis estadísticos como rho de Spearman, que es recomendado para determinar correlaciones en datos con distribución no normal o en el caso de variables ordinales en los que se requiere esta forma de aproximación no paramétrica (Martínez et al., 2009; Pita y Pértega, 1997) y regresiones logísticas que permiten estimar el efecto del miedo, la ira o la duda en el cambio del voto (Babbie, 2000).

La encuesta estuvo compuesta por 33 preguntas que contienen las siguientes categorías: datos demográficos, top of mind, escalas de calificación, fuentes, apreciación, percepción y emociones, afinidad política y cambios de decisión en el voto.

Con el propósito de incrementar la validez, se colocaron escalas de Likert para medir las apreciaciones personales sobre el Proyecto Tranvía, las que en el análisis fueron contrastadas con las de top of mind iniciales, a fin de que no existan contradicciones. De igual manera, las baterías de preguntas relacionadas con la percepción ante siete rumores específicos fueron validadas en un sondeo preliminar.

Las variables miedo/ira/incertidumbre (duda) fueron abordadas de manera directa a través de valoraciones con escalas Likert. Las preguntas partieron por validar el conocimiento o no de los rumores, las fuentes de donde provinieron esas afirmaciones, luego la credibilidad o no de estos y finalmente tres baterías de interrogantes para preguntar: "De los comentarios escuchados, califique del 1 al 5, siendo 1 nada y 5 totalmente, ¿̇uánta duda (o incertidumbre)/temor (o miedo)/ira (enojo o molestia) generaron en usted esos comentarios?”.

La variable cambio en el voto se evaluó a través de preguntas sobre su comportamiento en el voto: si votó por alcalde, por quién votó para alcalde, cuándo decidió el voto y también de manera directa: “ $¿ E s t o s$ comentarios generaron algún cambio en su forma de votar en las eleccio- nes para alcalde de Cuenca?”. Además se incluyó una pregunta adicional para evaluar el cambio en el voto, es decir, cuál era su preferencia inicial y cuál su decisión final.

\section{Resultados}

La encuesta se aplicó de manera aleatoria (tercer trimestre de 2014) entre los frentistas del centro histórico de las calles por las que pasará el tranvía. El total de frentistas está dividido en cuatro grupos, $71 \%$ corresponde a los arrendatarios de locales comerciales, $15 \%$ a propietarios de viviendas, $10 \%$ a arrendatarios de vivienda y $4 \%$ a propietarios de locales. La población de frentistas entrevistados es $62 \%$ femenina y $38 \%$ masculina, más de $68 \%$ se encuentra entre los 26 y 50 años. En cuanto a la formación académica, $51 \%$ indica haber cursado la secundaria y $33 \%$ la educación superior.

El $50 \%$ de los encuestados tuvo opiniones y comentarios negativos sobre el proyecto, lo cual deja entrever que el top of mind era principalmente contrario a la construcción del tranvía. Con respecto a qué sucederá con las estructuras de las casas una vez que se instale el tranvía, $61 \%$ dijo que piensa que se van a afectar o dañar las viviendas, sobre todo por la vibración, tan solo $26 \%$ dijo que no va a pasar nada con las casas.

$\mathrm{Al}$ referirse a los negocios, $54 \%$ piensa que con el paso del tranvía van a bajar sus ventas, perder o incluso cerrar y $28 \%$ indica que pueden existir mejoras en los negocios. Sobre la opinión del financiamiento del Proyecto Tranvía, $43 \%$ indicó no conocer sobre el tema y $23 \%$ dijo que fue una mala inversión y que existen otros proyectos y prioridades en la ciudad.

En cuanto al tranvía y la seguridad del medio de transporte, $60 \%$ de los encuestados piensa que será un transponte seguro. Con relación a los contratos firmados para la ejecución del proyecto, $60 \%$ dijo no conocer sobre el tema, $11 \%$ que son un negociado.

\section{Nivel de acuerdo con el tranvía}

A través de una escala de calificación de Likert, se consultó a los frentistas si estaban de acuerdo 
Figura 1. Validación de los rumores.

\section{¿Escuchó o no escuchó?}

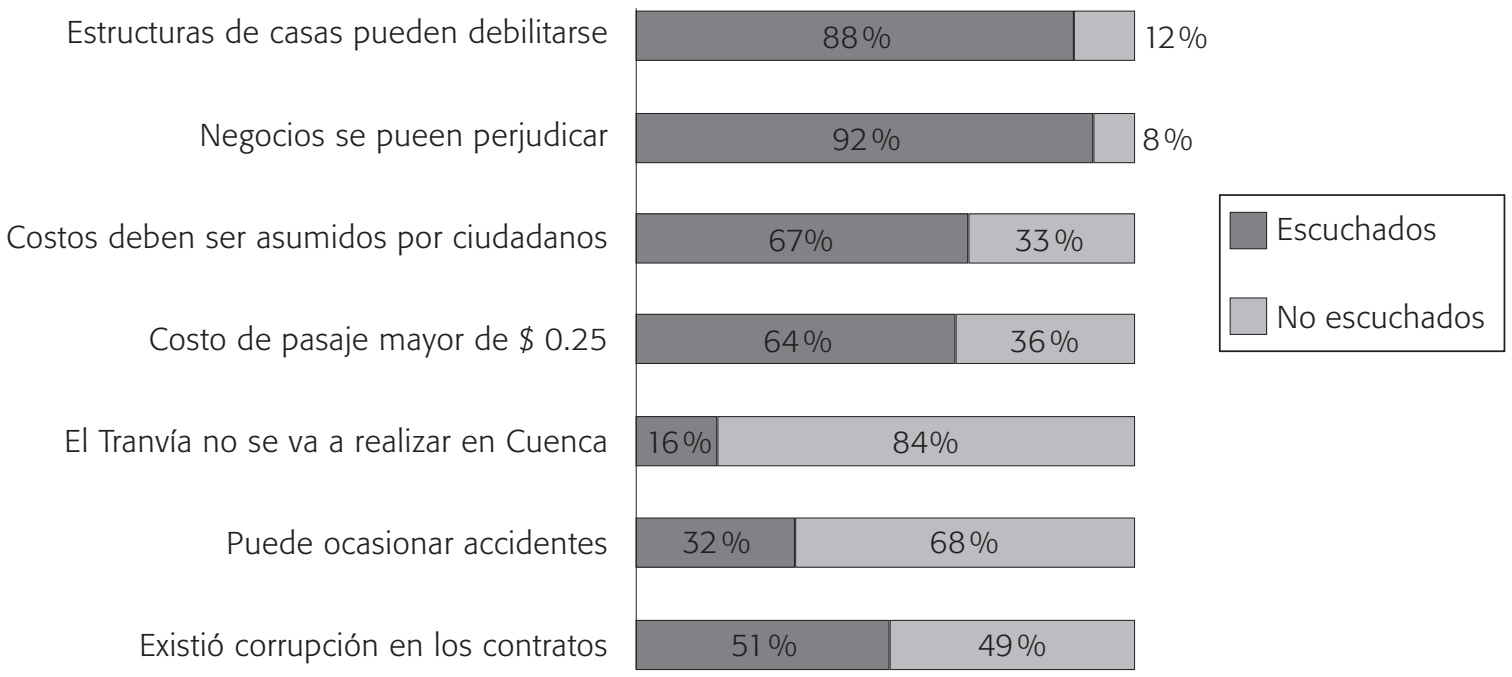

Información obtenida por encuesta aplicada por las autoras. Pregunta: "Se han recogido textualmente algunos comentarios acerca del Proyecto Tranvía. Permítame consultarle si usted ha escuchado alguno de ellos" ( $\mathrm{N}=273$ ).

con que el Tranvía se ejecute en Cuenca. La escala fue planteada del 1 al 5, en la que 1 es nada de acuerdo y 5 totalmente de acuerdo. El promedio en la preferencia sobre la realización del Tranvía en Cuenca fue de 2.38 (desviación estándar de 1.4). Mientras que el promedio sobre la preferencia que el tranvía pase por su calle fue de 1.87 (desviación estándar de 1.26).

Al comparar este tema con la intención de voto, se obtiene que, del total de los frentistas que votaron para alcalde $(\mathrm{n}=173), 44 \%$ de los votantes de Marcelo Cabrera no estaba de acuerdo con que el tranvía pase por su calle. En cambio, de los votantes de Paúl Granda, $11 \%$ no estaba de acuerdo con que el tranvía pase por su calle.

\section{Fuentes de información}

Para conocer los canales por los que llegan los mensajes, se les consultó cuál fue la fuente por la que escucharon por primera vez del Proyecto Tranvía. Un $33 \%$ dijo que la radio; $20 \%$, la prensa; $12 \%$, la televisión; y $11 \%$ indica que se enteró por el exalcalde Paúl Granda.

\section{Sobre comentarios y rumores}

Se consultó sobre cuáles de estos rumores habían sido escuchados por ellos, la fuente por la que los escucharon y sobre sus diversas reacciones (figura 1).

Todos los comentarios han sido escuchados por los frentistas en mayor o menor grado, la mayoría de ellos supera $50 \%$ de alcance. Algunos comentarios han sido escuchados casi por la totalidad de los frentistas, como es el caso del comentario "los negocios de los frentistas se van a perjudicar con el paso del tranvía”, que lo ha escuchado $92 \%$ de los consultados, o sobre que "con el paso del tranvía las estructuras de las casas pueden debilitarse", que lo ha escuchado $88 \%$.

Solo dos comentarios fueron escuchados por menos de la mitad de los frentistas. El comentario de que "el tranvía puede ocasionar accidentes" lo ha escuchado $32 \%$; y de que "el tranvía no se va a realizar en Cuenca”, $16 \%$.

\section{Fuente y credibilidad de los comentarios}

Sobre la fuente de información en seis de los siete comentarios escuchados, más de $50 \%$ los escuchó 
de amigos, vecinos o familia; sin embargo, en el caso puntual del comentario sobre que "el Tranvía no se va a realizar en Cuenca" (16\% escuchó este comentario), la fuente primaria fueron los candidatos. Al consultar a los frentistas qué tanto creyeron en los comentarios escuchados, los resultados son muy parejos, la mayoría se ha colocado en una posición intermedia al decir que ni cree, ni no cree, solo en el caso del comentario de que "el tranvía no se va a realizar en Cuenca", quienes lo escucharon indicaron en su mayoría que no creen en el comentario.

\section{Sentimientos o emociones ante los comentarios}

Para determinar los sentimientos o emociones implícitos en los comentarios escuchados, se utilizó una escala de calificación de Likert y se consultó en cada uno de los siete casos en qué medida el comentario les causó duda o incertidumbre, miedo o temor e ira, enojo o molestia (tabla 1).

En general, los comentarios sobre el Proyecto Tranvía generaron incertidumbre en más de $30 \%$ de los frentistas, miedo en más de $27 \%$ e ira en más de $41 \%$, cada uno en diferente grado. En seis de los siete rumores evaluados, la ira es el sentimiento predominante.

\section{Información confiable o rumor}

Se consultó a los frentistas cómo consideran los comentarios escuchados, entre información confiable, rumor o algo que se supone. Los comentarios fueron calificados mayoritariamente como rumores; sin embargo, alrededor de $30 \%$ los calificó como información confiable.

Un $78 \%$ de quienes consideraron los comentarios como información confiable votó por Marcelo Cabrera y $11 \%$ por Paúl Granda. En cambio, quienes consideraron los comentarios como rumor votaron $58 \%$ por Marcelo Cabrera y $26 \%$ por Paúl Granda. Es decir, quienes consideraron los comentarios confiables votaron menos por Granda (figura 2).

Al comparar estos resultados con las emociones, se obtuvo que, de quienes consideran los comentarios información confiable, $47 \%$ dice que le generó mucho miedo; en cambio, quienes consideran los comentarios rumores, $55 \%$ indicó que no les causó nada de miedo.

Asimismo de quienes opinan que los comentarios son información confiable, $61 \%$ dice que le generó mucha ira y molestia; en cambio, a $43 \%$ de quienes opinan que son rumores no les causó nada de ira. Es decir, los sentimientos de ira y

Tabla 1. Generación de emociones (duda, miedo e ira) frente al rumor escuchado

\begin{tabular}{lccc}
\hline \multicolumn{1}{c}{ Comentario } & $\begin{array}{c}\text { Duda } \\
\text { Media (de) }\end{array}$ & $\begin{array}{c}\text { Miedo } \\
\text { Media (de) }\end{array}$ & $\begin{array}{c}\text { Ira } \\
\text { Media (de) }\end{array}$ \\
\hline $\begin{array}{l}\text { Con el paso del tranvía las estructuras de las casas pueden } \\
\text { debilitarse }(\mathrm{n}=241)\end{array}$ & $2.81(1.26)$ & $2.55(1.29)$ & $3.05(1.44)$ \\
\hline $\begin{array}{l}\text { Los negocios de los frentistas se van a perjudicar con el paso del } \\
\text { tranvía }(\mathrm{n}=248)\end{array}$ & $2.87(1.29)$ & $2.66(1.33)$ & $3.16(1.43)$ \\
\hline $\begin{array}{l}\text { Los costos del proyecto van a ser asumidos por todos los } \\
\text { ciudadanos }(\mathrm{n}=181)\end{array}$ & $2.85(1.31)$ & $2.69(1.32)$ & $3.09(1.40)$ \\
\hline $\begin{array}{l}\text { El costo del pasaje va a ser mayor de \$0.25 ctv }(\mathrm{n}=174) \\
\text { El Proyecto Tranvía no se va a realizar en Cuenca }(\mathrm{n}=38)\end{array}$ & $2.92(1.3)$ & $2.68(1.35)$ & $3.11(1.46)$ \\
\hline El tranvía puede ocasionar accidentes $(\mathrm{n}=84)$ & $2.68(1.45)$ & $2.35(1.36)$ & $2.36(1.36)$ \\
\hline Existió corrupción en los contratos del tranvía $(\mathrm{n}=134)$ & $3.01(1.3)$ & $2.70(1.34)$ & $3.27(1.46)$ \\
\hline
\end{tabular}

Pregunta: "De los comentarios escuchados califique del 1 al 5, siendo 1 nada y 5 totalmente, ¿cuánta duda/temor/ira generaron en usted estos comentarios?". Los resultados se muestran sobre la media y la desviación estándar. El $n$ varía de acuerdo con el número de personas que manifestó haber escuchado el comentario.

Fuente: elaboración propia 
miedo están más presentes en quienes consideran la información como confiable.

\section{Rumor y elecciones}

Un $83 \%$ de los frentistas indica que votó por alcalde en Cuenca. De quienes votaron por alcalde, $56 \%$ dice que votó por Marcelo Cabrera, $19 \%$ por Paúl Granda y $15 \%$ indica que su voto es secreto.

Se consultó a los frentistas si los comentarios escuchados cambiaron en algo su forma de votar para alcalde de Cuenca. Un $82 \%$ dijo que no cambió y $18 \%$ dijo que sí cambió su forma de votar por los comentarios escuchados. De los frentistas que manifiestan que los comentarios cambiaron su forma de votar $(\mathrm{n}=41), 83 \%$ indica que votó por Marcelo Cabrera, $10 \%$ votó nulo y $7 \%$ dice que su voto es secreto.

Del total de votantes $(n=229) 46 \%$ indica que decidió su voto durante la campaña, $35 \%$ decidió antes de la campaña, $8 \%$ decidió una semana antes de las votaciones y un $8 \%$ decidió el mismo día de la elección.

Al hacer un cruce entre los que cambiaron su voto $(\mathrm{n}=41)$ por la decisión que tomaron, $51 \%$, que dijo que cambió de Alianza PAÍS a Igualdad, votó por Marcelo Cabrera; 33 \% , que no especificó cómo cambió su voto, también votó por Cabrera; y $11 \%$ de los que cambiaron su voto pero no especificaron cómo, votaron nulo.

Al comparar los frentistas que cambiaron su voto con las emociones expresadas, tenemos que a $75 \%$ de los consultados los comentarios considerados les generaron mucha duda e incertidumbre, a $72 \%$ mucha ira, enojo o molestia y a $41 \%$ mucho miedo o temor. Es importante también notar que de quienes cambiaron su voto $(n=41) 69 \%$ indicó que no estaba nada de acuerdo con que el tranvía se ejecute en Cuenca y $97 \%$ no estaba nada de acuerdo con que el tranvía pase por su calle.

Con la finalidad de establecer correlaciones entre las variables consideradas en este estudio y el cambio en el voto, se realizó una prueba de correlación rho de Spearman (tabla 2), dado que los datos no tienen una distribución normal (Martínez et al., 2009).

Existe una relación negativa entre el nivel de agrado por el candidato Marcelo Cabrera y el

Figura 2. Percepción de credibilidad de los comentarios contrastada con el voto.

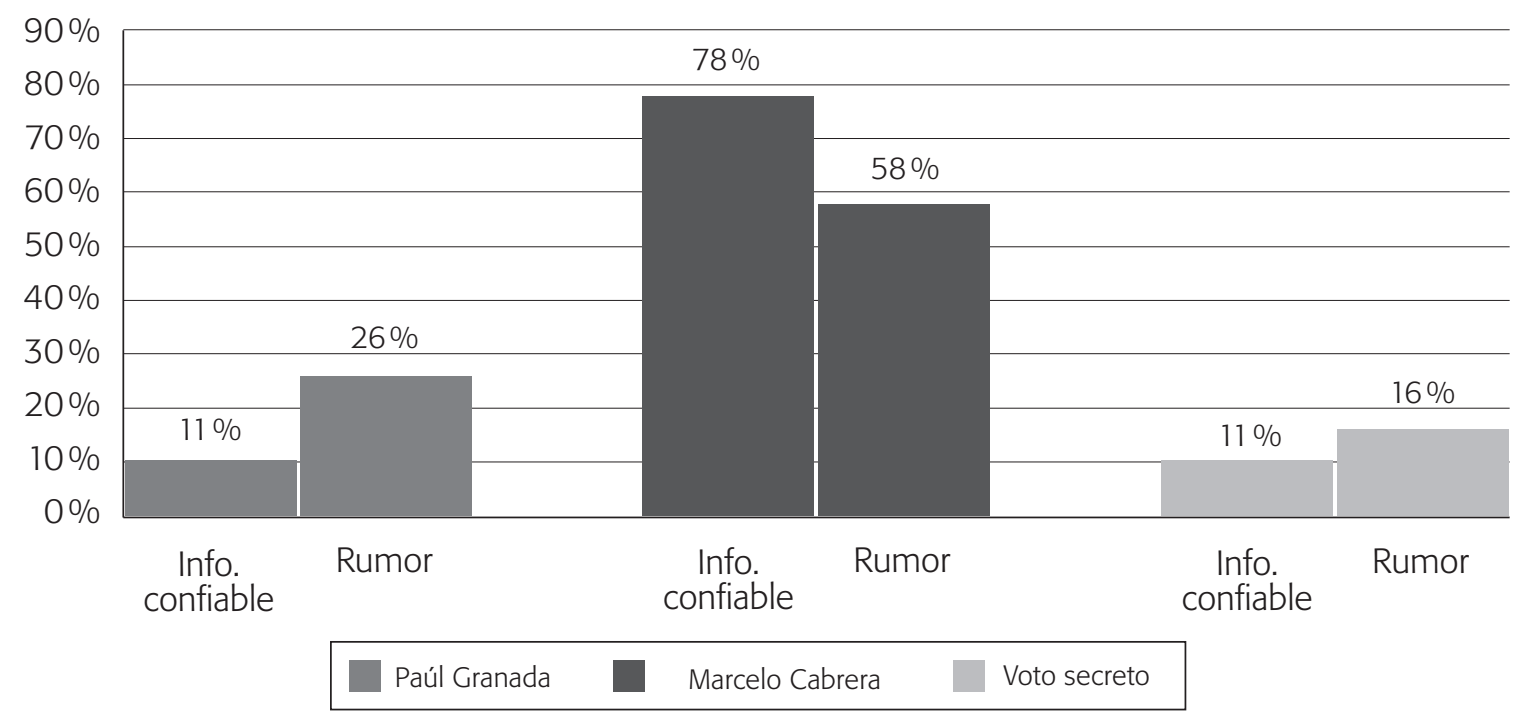

Preguntas: "¿En general, cómo calificaría a estos comentarios sobre el tranvía? Frenta a "¿Por quién votó para alcalde?". Los resultados se muestran sobre las opciones Información confiable y Rumor. Los porcentajes corresponden al promedio de los siete comentarios evaluados cruzado con la decisión del voto.

Fuente: elaboración propia 
Tabla 2. Análisis de la relación de las variables con el cambio del voto

Prueba de correlación rho de Spearman frente a la variable Cambio en el voto. Los números explican el tipo de relación entre las variables.

\begin{tabular}{lc}
\hline \multicolumn{1}{c}{ Variables } & $\begin{array}{c}\text { ¿Estos comentarios generaron } \\
\text { cambios en su forma de votar? }\end{array}$ \\
\hline Agrado por Marcelo Cabrera & $-0.173^{*}$ \\
\hline Agrado por Paúl Granda & $-0.241^{* *}$ \\
\hline Indique si está de acuerdo con que el Proyecto Tranvía se ejecute en & $-0.199^{* *}$ \\
\hline Cuenca & $-0.265^{* *}$ \\
\hline Indique si está de acuerdo con que el Proyecto Tranvía pase por esta calle & $0.141^{*}$ \\
\hline El tranvía puede ocasionar accidentes & $0.166^{*}$ \\
\hline Top of mind sobre el tranvía & $-0.228^{* *}$ \\
\hline
\end{tabular}

* La correlación es significativa en el nivel 0.05 (bilateral).

** La correlación es significativa en el nivel 0.01 (bilateral).

Fuente: elaboración propia

cambio en la forma del voto. Este tipo de relación también se da entre el agrado por Paúl Granda y el cambio en el voto, pero la correlación en el segundo es todavía más fuerte. Es decir, a menor agrado más probabilidades de cambiar el voto $(0.241 \mathrm{p}=0.01)$.

En los mismos términos, la correlación entre el nivel de acuerdo por la ejecución del tranvía en la ciudad y, más fuerte aún, en su calle, está asociado negativamente con el cambio del voto. Es decir, a menor acuerdo con el proyecto más opciones de cambio en el voto $(-0.265 \mathrm{p}=0.01)$.

En cuanto a la credibilidad de los rumores con correlación significativa con el cambio del voto, están el de que el tranvía puede ocasionar accidentes y la corrupción en los contratos. En este caso, a mayor credibilidad del rumor mayor posibilidad de cambiar el voto.

Tener una percepción (top of mind) negativa del proyecto está relacionada con el cambio en el voto, como lo demuestra la correlación $(-0.228 \mathrm{p}=0.01)$.

Se realizó una regresión logística con variables demográficas (edad, sexo, formación académica), y las tres variables de las emociones generadas por el rumor (miedo, ira y duda), para analizar la influencia de estas en el cambio del voto (tabla 3).
En este caso, los resultados de la regresión permiten establecer una relación significativa $(p \leq 0.01)$ entre la variable sexo y el cambio en el voto; en este caso, las mujeres son más susceptibles de experimentar cambios en sus decisiones debido a las reacciones ante los rumores. Los comentarios inciden positivamente en el cambio respecto del voto cuando han generado ira entre los ciudadanos $(p \leq 0.01)$. La incidencia de estas variables en el cambio del voto se estima en $22 \%$ (Nagelkerke R cuadrado = 0.224).

\section{Discusión}

El tranvía es un proyecto nuevo para Cuenca, que produce varios cambios en el sistema de transporte de la ciudad, lo cual ha hecho que se vea envuelto en una serie de comentarios y especulaciones, que lo han expuesto a opiniones diversas y a una percepción negativa de los frentistas del centro histórico. Esto puede estar relacionado con varios factores de influencia en la opinión de los individuos, entre ellos: un alto sentido de pertenencia, resistencia a cambios, sensibilidad en tiempos de campaña electoral.

\section{Factores de influencia}

La zona céntrica de Cuenca se caracteriza por su naturaleza turística, patrimonial y comercial. 
Tabla 3. Influencia de las emociones (miedo/ira/duda) ante comentarios negativos sobre el tranvía en el cambio del voto para alcalde de Cuenca 2014

Variable dependiente: “¿Esos comentarios generaron algún cambio en su forma de votar en las elecciones para alcalde de Cuenca?” ( $\mathrm{N}=273)$

\begin{tabular}{lcccccc}
\hline Variables en la ecuación & $\mathrm{B}$ & $\begin{array}{c}\text { Error } \\
\text { estándar }\end{array}$ & Wald & gl & Sig. & Exp(B) \\
\hline edad & -0.001 & 0.016 & 0.004 & 1 & 0.948 & 0.999 \\
\hline sexo(1 = hombre) & -1.355 & 0.481 & 7.944 & 1 & 0.005 & 0.258 \\
\hline Formación académica & 0.090 & 0.291 & 0.097 & 1 & 0.756 & 1.095 \\
\hline Miedo & 0.004 & 0.042 & 0.007 & 1 & 0.932 & 1.004 \\
\hline Ira & 0.094 & 0.036 & 6.769 & 1 & 0.009 & 1.098 \\
\hline Duda & 0.034 & 0.037 & 0.879 & 1 & 0.349 & 1.035 \\
\hline Constante & -3.229 & 1.071 & 9.094 & 1 & 0.003 & 0.040 \\
\hline
\end{tabular}

(Índice construido con la suma de respuestas sobre miedo/ira/duda frente al debilitamiento de estructuras, perjudicar los negocios, costos del proyecto asumidos por ciudadanos, costo del pasaje mayor a 25 ctv., que no se realice el proyecto, que el tranvía ocasione accidentes, que existe corrupción en los contratos. Escala de 5 puntos donde $1=$ Nada y $5=$ Totalmente Test de Cronbach $\alpha=0.77$ ).

Fuente: elaboración propia

Un $51 \%$ del total de frentistas ha permanecido en este espacio por más de cinco años, por lo que se puede identificar en este grupo un fuerte empoderamiento del espacio físico, pues, al pasar de los años, se ha generado en ellos un sentido de pertenencia y, en el caso de los comerciantes, una estabilidad laboral con respecto a sus negocios. La resistencia a los cambios podría explicar cierta negatividad, sin embargo, hay que considerar el proceso de entrada o salida de la modernidad planteado por García Canclini (2000) en su análisis sobre la "hibridación". La modernidad en América Latina ingresa (o no) no solo por el intento de reflejar "las optimizadas imágenes de la modernidad europea" o por la resistencia local a reproducirlas. La modernidad en América Latina se explica por la transformación del "mestizaje" a las culturas híbridas en que las tradiciones no son consideradas contrarias a la modernidad y donde las ideas "importadas" se incorporan en las "tradiciones y reelaboraciones de la propia historia cultural" (Barbero, 2001, párr. 8).

Es de notar que, si bien existe una resistencia al proyecto en general, esta se acentúa fuertemente por el hecho de que el tranvía atraviesa la calle del frentista, el desacuerdo se vuelve más visible en el momento de sentirse afectado directamente y disminuye cuando se consulta la ejecución del proyecto en Cuenca. Como se decía, el mensaje se vuelve más sensible por la predisposición personal.

\section{Rumores}

La investigación confirma que los siete rumores escogidos para el estudio fueron escuchados por los frentistas, cinco de los siete casos por más de la mitad de estos, tras lo cual se comprobó que esta información era manejada por el colectivo.

Además, si bien se evidenció que los medios masivos eran la fuente por la que más información llegaba a las personas, en el caso de los rumores, la fuente cambia totalmente, pues, en seis de los siete casos, los comentarios vinieron de vecinos, amigos o familia en más de $50 \%$ de los frentistas, lo cual comprobó que esta información viene de conversaciones circulantes, mas no de fuentes oficiales; salvo en el caso puntual del comentario "el tranvía no se va a realizar en Cuenca”, donde identifican como la fuente 
principal a los candidatos. Un $47 \%$ de los entrevistados indicó que no se había acercado nadie del municipio a hablarle de este, lo cual comprueba lo manifestado por Allport y Postman (1947), que ante la importancia del tema y la ambigüedad de la información, existe mayor oportunidad para la propagación del rumor.

\section{Rumores y emociones}

La incertidumbre, el miedo y la ira son sentimientos que producen ansiedad en las personas, por lo que se podría afirmar que en el caso de los rumores negativos expuestos sobre el tranvía las emociones contribuyeron a la negatividad y el pesimismo con respecto al proyecto. Esto pudo conducir a diferentes reacciones que la teoría ha manifestado, es decir, búsqueda de mayor información y, como en este caso, cambio de opinión en la dirección a la que la información le condujo (Hansen y Pedersen, 2014; Sciarini y Kriesi, 2003; Weeks y Garrett, 2014; Weeks, 2015).

Existe una diferencia clara cuando se analizan las percepciones frente a la decisión de voto. Quienes votaron por Marcelo Cabrera tienen una posición mayormente negativa ante el proyecto, es decir, estaban en contra de que se ejecute; en cambio, quienes votaron por Paúl Granda, impulsor del Tranvía, opinan de forma positiva.

Al no contar los comentarios expuestos en campaña con una fuente clara y verificable, fueron catalogados por el colectivo en más de $50 \%$ como rumores y en $30 \%$ como información confiable. Esta relativa credibilidad otorgada al rumor es considerada como un factor de influencia en la decisión de voto, ya que quienes confiaron en la información prefirieron votar por Cabrera, tomando en cuenta que Granda era quien más hablaba de la ejecución del proyecto.

La intensidad de las emociones también dependió del nivel de confiabilidad otorgado al comentario. Cuanto más confiable, mayor ira (60\%) y mayor temor (47\%). La confianza supone el cumplimiento de lo dicho; los individuos que confían se sienten abiertos a expresar sus emociones con respecto a algo que consideran cierto.

\section{Rumores y cambio de voto}

Al consultar abiertamente a los frentistas que votaron para alcalde si los comentarios escuchados generaron cambios en su forma de votar, $18 \%$ afirma que sí cambió su forma de votar. De quienes dicen que cambiaron su voto, $51 \%$ indica que lo hizo de Paúl Granda a Marcelo Cabrera; y $33 \%$, que no contesta cómo cambió, dice que votó por Marcelo Cabrera; es decir, $84 \%$ de frentistas que cambió su voto votó por Cabrera. Además, este grupo que cambió su voto manifestó en 97 \% que no estaba de acuerdo con que el tranvía pase por su calle, con lo cual se hace notorio de nuevo que la predisposición personal influye en las decisiones.

Con relación a las emociones, quienes cambiaron su voto manifestaron que los comentarios escuchados les causaron $75 \%$ mucha incertidumbre, $41 \%$ mucho miedo y $72 \%$ mucha ira. Estos porcentajes asociados con el análisis de regresión logística son la evidencia de que las emociones, en particular la ira, generadas por los rumores provocaron efectos en la forma de votar de los frentistas.

\section{Conclusiones y recomendaciones}

En la transmisión de mensajes, como es natural en la comunicación humana, el interlocutor tiende a poner su estilo, con una dosis de pensamientos o emociones propias. Por tanto, el rumor tiene, además, la cualidad de estar cargado de motivantes emocionales. Estas emociones combinadas con la credibilidad que le otorga su cercano interlocutor (amigos, vecinos, familiares) son un motivante para su circulación y para la generación del efecto evaluado (Zhao, Liu y Wang, 2016).

En este estudio, fue la ira, principalmente, la emoción que explica de mejor manera el cambio en el voto. El efecto de la ira, asociada a la desinformación, está correlacionada con la preferencia política y la identificación del emisor. Quienes escucharon los rumores y decidieron tomarlos como confiables optaron por evitar a quien identificaron como responsable del proyecto y cambiaron su voto. Este tipo de reacciones se asocian con estudios, como el de Weeks (2015), quien afirma que la ira y la ansiedad 
moderan el efecto de la preferencia política en la sensibilidad a la desinformación o rumor.

A efectos de este estudio, se planteó como hipótesis que los rumores en torno al Proyecto Tranvía generaron miedo/ira/duda en los frentistas del centro histórico, lo cual influyó en su decisión de voto. Los resultados del análisis de regresión logística permiten confirmar la hipótesis en torno a la ira generada por los rumores, y que el conjunto de variables analizadas influyen en $22 \%$ en el cambio del voto.

Finalmente, se considera que en una contienda cerrada, como la de la Alcaldía de Cuenca de 2014, debieron haber existido varios factores influyentes que transformaron la decisión de los votantes en torno a los 45 días de campaña. Si bien no se podría decir que los rumores cambiaron los resultados, la información confirma que fue uno de los factores de influencia.

En comunicación estratégica, se conoce que es imposible evitar el rumor, por tanto, lo correcto es gestionarlo. En este estudio, se ha identificado que ante la presencia de rumores existen algunas variables que facilitan su propagación y credibilidad. En primer lugar, ausencia de información oficial, posteriormente un rechazo al proyecto objeto del rumor, preferencias políticas preestablecidas que impiden dar crédito a información que contrarreste el rumor y luego el efecto del rumor en las emociones, que fue el enfoque de este estudio, donde se ha demostrado que tanto el miedo como la incertidumbre y la ira inciden en el cambio en el voto. Sin embargo, de las tres emociones, la ira tiene una contribución mayor.

El estudio del rumor y las reacciones afectivas o emocionales que pueda generar en los individuos implica connotaciones de trascendencia en los procesos democráticos, ya que su presencia o manipulación pone en peligro la calidad de la información a la que accede el votante, interviene de manera intencionada en sus reacciones y emociones y, como consecuencia, el votante toma decisiones sobre la base de una información pobre o deficiente.

Más allá de los resultados electorales del caso de estudio, esta investigación confirma la influen- cia del rumor y su efecto en el cambio de opinión del votante. Por tanto, no es exagerado coincidir con algunos investigadores que consideran que el empleo del rumor como técnica de campaña puede ser un peligro para la democracia, en la medida en que la información, transmitida vía rumor, puede ser manipulada con intenciones que se alejan del entorno deliberativo y de acceso oportuno a información de calidad, que se espera pueda ser una campaña política.

\section{Agradecimiento}

Un especial reconocimiento a los revisores por sus valiosos aportes y comentarios.

\section{Referencias}

Allport, G. y Postman, L. (1947). Analysis of rumor. Public Opinion Quarterly, 10, 501-517.

Babbie, E. (2000). Fundamentos de la investigación social. México: International Thomson Editores.

Bacalao, M. (2012). El rumor en la política. En Centro interamericano de gerencia política. Recuperado de http://www.centropolitico. org/el-rumor-en-la-politica/

Barbero, J. M. (2001). Sobre culturas híbridas: estrategias para entrar y salir de la modernidad. En Magazín Dominical. Recuperado de http://nestorgarciacanclini.net/index.php/ hibridacion-e-interculturalidad/73-resenasobre-culturas-hibridas-estrategias-paraentrar-y-salir-de-la-modernidad

Contreras, J. (2001). Rumores: voces que serpentean. Revista Latina de Comunicación Social, 40, 1-19. Recuperado de http:/www.ull.es/publicaciones/ latina/2001/latina40abr/108contreras.htm

Daignault, P., Soroka, S. y Giasson, T. (2013). The perception of political advertising during an election campaign: A measure of cognitive and emotional effects. Canadian Journal of Communication, 38(2), 167-186.

El País (21 marzo 2007). Procter \& Gamble derrota a su leyenda urbana. Recuperado de http:// economia.elpais.com/economia/2007/03/21/ actualidad/1174465978_850215.html 
El Tiempo (8 octubre 2008). Falsa noticia sobre paro cardiaco del presidente de Apple abre debate sobre periodismo ciudadano. Recuperado de http://www.eltiempo.com/archivo/ documento/CMS-4590687

El Tiempo (23 febrero 2014). Cabrera gana la Alcaldía de Cuenca y Carrasco la Prefectura del Azuay. Recuperado de http://www.eltiempo.com.ec/ noticias-cuenca/138275-cabrera-gana-la-alcaldaa-de-cuenca-y-carrasco-la-prefectura-del-azuay/

Escalante, C. (2007). El contacto directo con electores y el uso del correo. En Comunicación Política (pp. 205-217). Quito: Quipus, Ciespal.

Fernández, A. (2012). Psicología de masas, identidad social, epidemias y rumores: la influenza en México. Sociológica, 27(76), 189-230. Recuperado de http://www.redalyc.org/articulo. oa? id $=305025286006$

Fernández,C. B. y Dell'Oro, J.(2011). Campañaspolíticas exitosas 2.0. Ciudad de Guatemala: Fundación Konrad Adenauer . Recuperado de http://www. kas.de/guatemala/es/publications/31214/

Fernández, I., Martín, C. y Páez, D. (1999). Emociones y conductas colectivas en catástrofes: ansiedad y rumor y conductas de pánico. En J. Apalategui (ed.), La anticipación de la sociedad: psicología social de los movimientos sociales (pp. 281-342). Valencia: Promolibro.

Gallego Reinoso, F. (2010). Cómo abordar los rumores: manual para comprenderlos y diseñar estrategias para contenerlos. Barcelona: Diputación de Barcelona. Recuperado de http:// www.getxo.eus/DocsPublic/inmigracion/ SENSIBILIZACION/ANTIRUMORES/ Como_abordar_Rumores.pdf

García Canclini, N. (2000). Noticias recientes sobre hibridación. Revista Transcultural de Música, 7. Recuperado de http://www.redalyc. org/articulo.oa? $\mathrm{id}=82200702$

García Escribano, J. J. y Ortiz García, P. (2013). Marco de análisis para el estudio de las campañas electorales y sus efectos sobre el voto en la región de Murcia. Murcia, Ecuador: Universidad de Murcia. Recuperado de https://digitum. um.es/xmlui/handle/10201/30400
García Dueñas, L. (2006). La trascendencia de la campaña del "miedo" en las elecciones de 2004 y la propaganda del "peligro" en México en 2006. Realidad, 109, 375-388.

Gobierno Autónomo Descentralizado de Cuenca (2014). Informe de gestión 2014. Cuenca.

Hansen, K. M. y Pedersen, R. T. (2014). Campaigns matter: How voters become knowledgeable and efficacious during election campaigns. Political Communication, 31(2), 303-324.

Martínez, R., Tuya, L., Martínez, M., Pérez, A. y Cánovas, A. (2009). El coeficiente de correlación de los rangos de Spearman: caracterización. Revista Habanera de Ciencias Médicas, 8(2). Recuperado de http://scielo.sld.cu/scielo. php? script $=$ sci_arttext $\&$ pid $=$ S1729-519X200 $9000200017 \& \operatorname{lng}=\mathrm{es} \& \mathrm{nrm}=\mathrm{iso} \& \mathrm{t} \operatorname{lng}=\mathrm{es}$

McClosky, H. y Chong, D. (1985). Science: Similarities and differences between left-wing and right-wing radicals. British Journal of Political Science, 15(3), 329-363. http://doi.org/10.1017/ S0007123400004221

Muñiz, R. (2010). Comunicación integral y marketing. En R. M. González (ed.), Marketing del siglo XXI (3. a ed.). Madrid: Centro de Estudios Financieros.

Ochoa, O. (2012). El poder del rumor político. Recuperado de http://www.soberania.org/ Articulos/articulo_7101.htm

Peytibi, X. (2012). La campaña del miedo. Recuperado de http://www.xavierpeytibi. com/2012/10/22/la-campana-del-miedo/

Pita, S. y Pértega, S. (1997). Relación entre variables cuantitativas. Cuadernos de Atención Primaria, 4, 141-144. Recuperado de http:// www.fisterra.com/gestor/upload/guias/ var_cuantitativas2.pdf

Schemer, C. (2012). Reinforcing spirals of negative affects and selective attention to advertising in a political campaign. Communication Research, 39, 413-434.

Sciarini, P. y Kriesi, H. (2003). Opinion stability and change during an electoral campaign. International Journal of Public Opinion Research, 15(4), 431-453. 
Sojo, I. (1998). La campaña electoral vista desde la perspectiva de la propaganda de ataque y el rumor. Recuperado de http://www.ull.es/ publicaciones/latina/a/02civan.htm

Vélaz, J. I. (1993). Los rumores: ¿barreras o medio de comunicación? Comunicación y Sociedad, $6(1$ y 2$), 8$.

Weeks, B. E. (2015). Emotions, partisanship, and misperceptions: How anger and anxiety moderate the effect of partisan bias on susceptibility to political misinformation. Journal of Communication, 65, 699-719.

\section{Notas}

1. Para referencias sobre ejemplos de aplicación del rumor, revisar casos de compañías como Apple (El Tiempo, 2008), Procter \& Gamble (El País, 2007) y la estrategia del rumor de la que fue víctima el candidato Handal del Frente Farabundo Martí en Honduras (García, 2006).

2. Un clásico es la publicidad para la campaña de Lyndon Johnson con una niña que corta pétalos como analogía del conteo regresivo de la explosión de una bomba
Weeks, B. E. y Garrett, R. K. (2014). Electoral consequences of political rumors: Motivated reasoning, candidate rumors, and vote choice during the 2008 U.S. presidential election. International Journal of Public Opinion Research, 26(4), 401-422.

Zaller, J. R. (1992). The nature and origins of mass opinion. Cambridge: Cambridge University Press.

Zhao, Z. J., Liu, Y. M. y Wang, K. X. (2016). An analysis of rumor propagation based on propagation force. Physica A: Statistical Mechanics and its Applications, 443, 263-271.

atómica. Una seria acusación al candidato oponente (Peytibi, 2012).

3. Cuenca, capital de la provincia del Azuay, cuenta con más 500000 habitantes y está ubicada al sur del país. Fue declarada por la Unesco patrimonio cultural de la humanidad en 1999.

4. Dato obtenido de la sección "Mapas" y "Planos" de la página www.cuenca.gob.ec de la Alcaldía de Cuenca.

Cómo citar este artículo

Ávila, C. y Cabrera, G. (2016). El efecto del rumor en el cambio del voto: la ira, el miedo y la incertidumbre generados por el rumor en procesos electorales y sus contribuciones en las decisiones del votante. Signo y Pensamiento, 35(69), 100-116. http://dx.doi.org/10.11144/Javeriana.syp35-69.ercv 
